\title{
PERFORMANCE OF CONCRETE BY USING ALBUMEN, YOLK AND MILK
}

\author{
Sara Mirzabagheri ${ }^{\mathbf{a}^{*}}$, F. Vatankhah ${ }^{\mathrm{b}}$, Zeynab Ziaee $^{\mathrm{b}}$, Ghazaleh Derhamjani ${ }^{\mathrm{b}}$, \\ Sahar Maharati ${ }^{b}$ H. Aslani ${ }^{b}$ \\ a* Civil Engineering Division, Faculty of Engineering, Parand Branch, Islamic Azad University \\ Parand, Tehran, Iran, e-mail: sara_mirzabagheri@yahoo.com \\ ${ }^{\mathrm{b}}$ Young Researchers and Elite Club, Parand Branch, Islamic Azad University, Parand, Tehran, Iran
}

Received: 13.03.2018 / Accepted: 11.04.2018 / Revised: 17.05.2018 / Available online: 31.05.2018

DOI: 10.2478/jaes-2018-0009

KEYWORDS: Concrete compressive strength, Concrete tensile strength, Albumen, Yolk.

\begin{abstract}
:
In ancient structures such as Jabalieh dome at Kerman and Dokhtar Bridge at Mianeh in Iran, it was said that egg and in some cases egg and camel milk were used in the mortar. Thus, it was imagined that the stability of these structures were based on these traditional materials. Therefore egg parts and also camel milk were used as a portion of water in the concrete to evaluate this traditional theory. For this purpose, 16 concrete mix designs included 144 cubes, 16 cylinders and 16 prisms were casted. Various percentages of albumen, yolk or camel milk were used. Results showed that by substituting $0.5 \%$ of water content with albumen, compressive strength was similar to control specimen. But splitting tensile strength and three-point flexural strength were $7.2 \%$ and $18.9 \%$ higher than control specimen, respectively. Moreover, because of camel milk's fat, usage of this material was not suggested.
\end{abstract}

\section{INTRODUCTION}

Usage of natural materials in constructing the structures has long been considered. It is said that some ancient structures around the world had been constructed with egg and milk as a part of their mortar.

In 2010 the effect of albumen on foamed concrete was investigated (Bing, 2010). Three types of mixtures were casted. $1 \%$ and $5 \%$ albumen were used to study albumen effect on compressive strength, flexural strength and drying shrinkage. It was seen that $1 \%$ egg albumen foamed concrete had higher compressive strength and flexural strength than control specimens. The coconut fiber and egg albumen were used in concrete mixture by Siang (2010). Three types of mixture were prepared i.e. control mixture without additives, mixture with $0.1 \%$ coconut fiber and $1 \%$ albumen, mixture with $0.5 \%$ coconut fiber and 5\% albumen. Test results showed that utilizing $0.1 \%$ coconut fiber and $1 \%$ albumen in the mixture resulted in higher strength than mixture with $0.5 \%$ coconut fiber and 5\% albumen. The effect of albumen and eggshell on compressive strength of mortar was investigated by Yusef (2014). Results showed that with addition of $1 \%$ albumen of the total volume of mortar, compressive strength increased. It is worth mentioning that the amount of cement did not increased and the water to cement ratio was consistent with control mixture.
Moreover, eggshell as a waste material was used in many investigations to produce green concrete. Green concrete also called echo-friendly concrete reduces $\mathrm{CO}_{2}$ emissions, waste water etc. Effect of using eggshell as partial replacement of cement in mortar was investigated by Gowsika et al. (2014). 5 to $30 \%$ of cement was replaced with eggshell. It was concluded that compressive strength of mortar decreased by increasing percentage of eggshell. In 2015, rice husk ash and eggshell powder were used in concrete as a replacement of cement (Qureshi et al., 2015). Compressive strength and flexural strength of the specimens with rice husk ash and eggshell powder were greater than control specimen. Moreover, Eggshell powder and fly ash were substituted a portion of cement by Dhanalakshmi et al. (2015). The percentage of eggshell powder varied from $0 \%$ to $12.5 \%$. Fly ash was added to the concrete with optimum eggshell powder. It was concluded that concrete with eggshell had greater compressive strength, splitting tensile strength and flexural strength than control concrete ones. In 2016, eggshell and silica foam were used as partial replacement of cement to produce lightweight concrete (Dixit et al., 2016). Increase of compressive, tensile and flexural strengths was obtained.

Other additives have also been used to reduce cement or aggregate in the concrete mixture. Fly ash is one of the materials used in concrete mixture. In 1982 fly ash and condensed silica-fume were used in concrete (Mehta, 1982). 
It was concluded that compressive strength of the concrete with additives was higher than the mixture without these materials. Fly ash and slag were used by Thomas and Bamforth (1999). It was seen that after few years chloride ingress decreased in the concrete with additives. Recycled glass and fly ash were another combination used in precast concrete (Meyer and Xi, 1999). Fly ash was also used in self-compacting concrete and an economical SCC was produced (Bouzoubaa and Lachemi, 2001). In 2004, the effect of fly ash with nano- $\mathrm{SiO}_{2}$ was investigated $(\mathrm{Li}, 2004)$. An increase in the strength of concrete was observed. Moreover, Teixeira et al. (2016) used two types of fly ashes. Beneficial effect of fly ashes was investigated.

Zeolite is another additive used in concrete. In 2009, a modified zeolite was used and optimum proportion in the range of $0.4 \%$ to $0.6 \%$ was achieved (Ikotum, 2009). Natural zeolite was utilized in 2016 to study long-term behaviour of concrete (Markiv et al., 2016). After 180 days, the specimens with zeolite showed higher compressive strength than control specimen. Moreover, chloride penetration resistance of concrete with and without zeolite was studied by Valipour et al. (2017). The range between $10 \%$ and $20 \%$ was obtained as an optimum range for usage of zeolite.

In order to investigate the effect of albumen, yolk and camel milk on performance of concrete, 16 concrete mixtures were used. Various percentages of these materials were utilized. Because of the nature of egg and milk, these materials were substituted a portion of water. 144 cubes, 16 cylinders and 16 prisms were casted. 7, 14 and 28-days compressive strength of the specimens were tested. Moreover, after 28 days, splitting tensile strength and flexural strength of the mixtures were obtained by testing cylinders and prisms, respectively.

\section{MATERIALS AND METHODS}

Based on legends, it was said that egg was used in the mortar of some ancient structures such as Jabalieh dome at Kerman and Dokhtar Bridge at Miyaneh in Iran. Moreover, it was said that camel milk was also used in the structure of Jabalieh dome. Therefore, it was decided to evaluate the effects of using albumen, yolk and camel milk in concrete. Figures 1 and 2 show Jabalieh dome and Dokhtar Bridge, respectively.

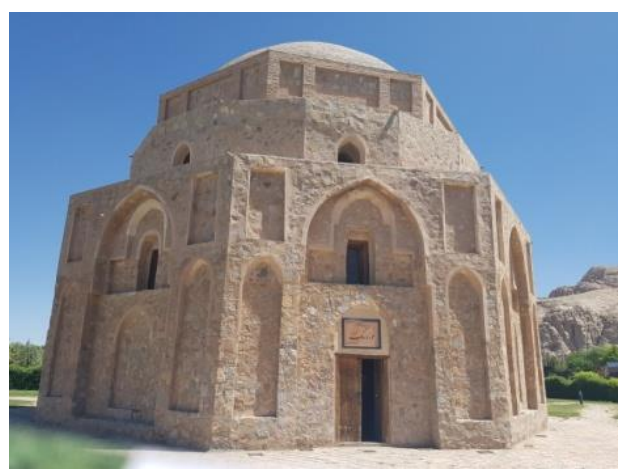

Figure 1. Jabalieh dome at Kerman, Iran

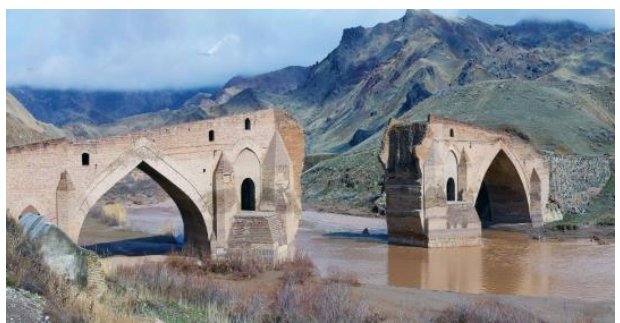

Figure 2. Dokhtar Bridge at Miyaneh, Iran

For this purpose, albumen and yolk were used instead of a portion of water in concrete. Moreover, the mixture of these two was also utilized. Camel milk was another material used instead of a portion of water in concrete.

\subsection{Anatomy of an Egg}

9-12\% of the egg is eggshell, 60-63\% albumen and 30-33\% yolk. The major part of eggshell is calcium carbonate $\left(\mathrm{CaCO}_{3}\right)$ crystals. Figure 3 shows anatomy of an egg.

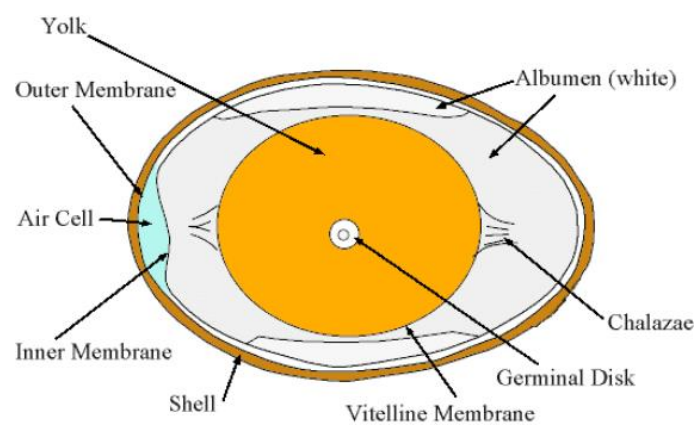

Figure 3. Anatomy of an egg

\subsection{Concrete Mix Proportions}

16 concrete mix designs were casted. One of the concrete mix designs was used as control specimens without any parts of egg or milk. In order to study the effect of albumen on concrete performance, $0.25,0.5,1$ and 1.5 percent of water were substituted with albumen (entitled W specimens). Moreover, $0.25,0.5,1$ and 1.5 percent of water were substituted with yolk to evaluate concrete performance with the use of yolk (entitled $\mathrm{Y}$ specimens). Besides, albumen and yolk were used together with the percent of $0.15,0.25$ and 0.5 (entitled WY specimens). Camel milk was another material substituted the water with the percent of 25, 50, 75 and 100\% (entitled M specimens).

In all of these concrete mix designs, nine $15 \times 15 \mathrm{~cm}$ cube, one standard cylinder and one beam with the size of $10 \times 10 \times 50 \mathrm{~cm}$ were casted. Cube specimens were tested after 7, 14 and 28 days for compressive strength. Cylinder specimens were tested after 28 days for tensile strength. Moreover, three-point flexural test was conducted on the beams. The mix proportions of the specimens are listed in Table 1. 
Table 1. Concrete mix proportions of the specimens $\left(\mathrm{kg} / \mathrm{m}^{3}\right)$

\begin{tabular}{|c|c|c|c|c|c|c|c|c|}
\hline Specimen & Water & Cement & $\begin{array}{c}\text { Fine } \\
\text { Aggregate }\end{array}$ & $\begin{array}{c}\text { Coarse } \\
\text { Aggregate }\end{array}$ & Albumen & Yolk & Egg & Camel Milk \\
\hline S & 200 & 426 & 824 & 898 & - & - & - & - \\
\hline W0.25 & 199.5 & 426 & 824 & 898 & 0.5 & - & - & - \\
\hline W0.5 & 199 & 426 & 824 & 898 & 1 & - & - & - \\
\hline W1 & 198 & 426 & 824 & 898 & 2 & - & - & - \\
\hline W1.5 & 197 & 426 & 824 & 898 & 3 & - & - & - \\
\hline Y0.25 & 199.5 & 426 & 824 & 898 & - & 0.5 & - & - \\
\hline Y0.5 & 199 & 426 & 824 & 898 & - & 1 & - & - \\
\hline Y1 & 198 & 426 & 824 & 898 & - & 2 & - & - \\
\hline Y1.5 & 197 & 426 & 824 & 898 & - & 3 & - & - \\
\hline WY0.15 & 199.7 & 426 & 824 & 898 & - & - & 0.3 & - \\
\hline WY0.25 & 199.5 & 426 & 824 & 898 & - & - & 0.5 & - \\
\hline WY0.5 & 199 & 426 & 824 & 898 & - & - & 1 & - \\
\hline M25 & 150 & 426 & 824 & 898 & - & - & - & 50 \\
\hline M50 & 100 & 426 & 824 & 898 & - & - & - & 100 \\
\hline M75 & 50 & 426 & 824 & 898 & - & - & - & 150 \\
\hline M100 & 0 & 426 & 824 & 898 & - & - & - & 200 \\
\hline
\end{tabular}

\section{EXPERIMENTAL RESULTS AND DISCUSSION}

\subsection{Compressive Strength}

As mentioned before, nine cube specimens were tested for compressive strength after 7, 14 and 28 days. Figure 4 shows a specimen in compressive test machine. Average of compressive strengths for 7, 14 and 28 days is presented in Figures 5 to 7, respectively.

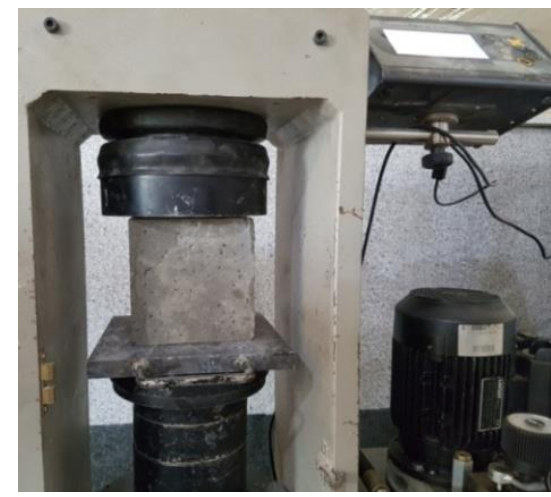

Figure 4. Compressive strength test

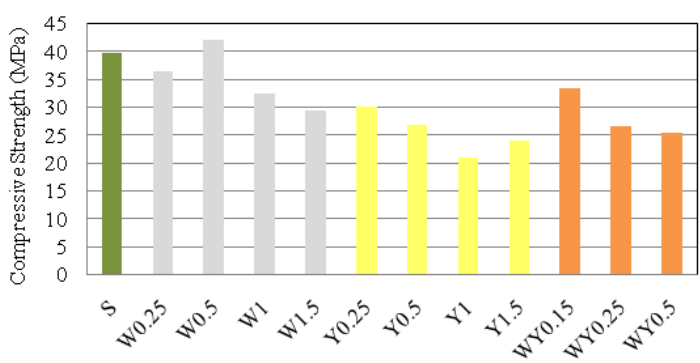

Figure 5. 7-days compressive strengths of cube specimens

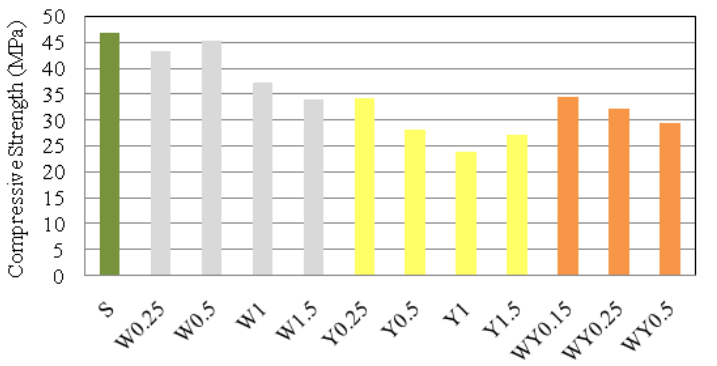

Figure 6. 14-days compressive strengths of cube specimens

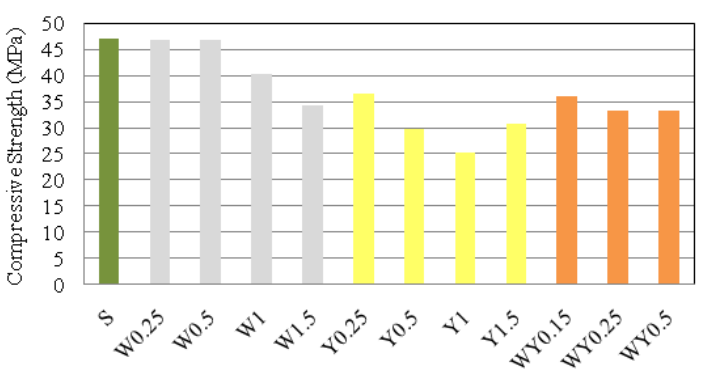

Figure 7. 28-days compressive strengths of cube specimens

As can be seen in the Figure 5, in the specimens with albumen, W0.5 which contains $0.5 \%$ albumen had the highest 7-days compressive strength.

Moreover, in the specimens with yolk, the specimen with $0.25 \%$ yolk had the highest compressive strength and among the specimens with combination of albumen and yolk, $0.15 \%$ resulted in the best 7-days compressive strength.

Similar trend was seen after 14 days and 28 days. By comparison of all 12 specimens after 28 days, it could be seen that the specimens in which $0.25 \%$ and $0.5 \%$ water content were substituted with albumen, 28-days compressive strengths were 
similar to control specimen. But other specimens had lower compressive strengths.

It is worth noting that, the specimens with camel milk had very low compressive strengths. Therefore the results were not in the diagrams of Figures 5 to 7 . The reason for low strengths of the specimens could belong to the camel milk's fat which prevented from the hardening procedure of the concrete.

\subsection{Splitting Tensile Strength}

Although, concrete is not designed to resist direct tensile stress, but evaluation of the load in which cracks propagate is valuable. One of the tests to achieve tensile strength of the concrete is splitting tensile strength. A standard cylinder with the size of $15 \mathrm{~cm} \times 30 \mathrm{~cm}$ is placed horizontally in a special fixture. Then this fixture and specimen are placed in a universal testing machine (Figure 8). Due to indirect tensile stress, the specimen splits into two halves.

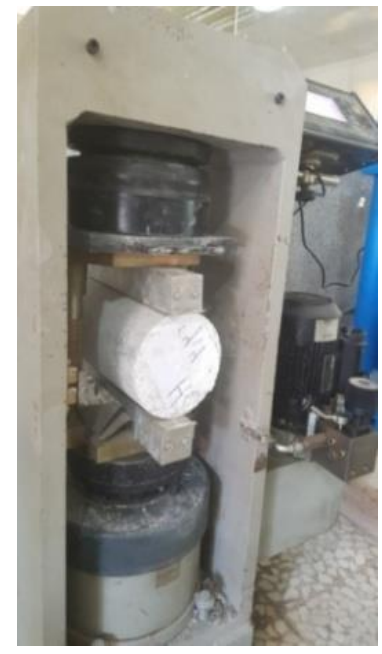

Figure 8. Tensile strength test

Splitting tensile strength of concrete can be achieved by Eq. 1 .

$$
f_{t}=\frac{2 P}{\pi D L}
$$

$\mathrm{P}, \mathrm{D}$ and $\mathrm{L}$ are compressive load at failure, diameter and length of cylinder, respectively.

Figure 9 presents splitting tensile strengths of the specimens calculated based on Eq. 1. As can be seen, the values of splitting tensile strength increased by increasing the percentage of albumen up to $1 \%$. Moreover, in the specimens with yolk, the specimen with $0.25 \%$ yolk, and among the specimens with combination of albumen and yolk, $0.15 \%$ resulted in the highest tensile strength. The specimens with 0.5 or $1 \%$ albumen had the highest values of splitting tensile strength in all of the specimens.

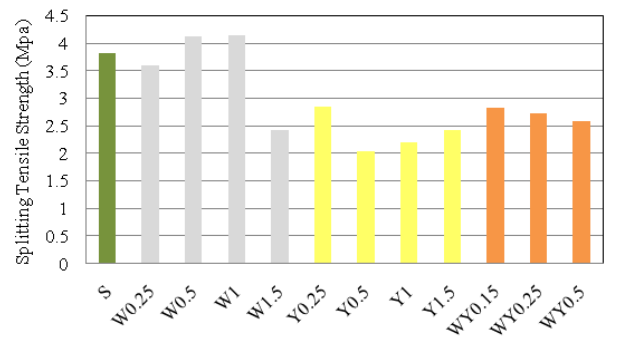

Figure 9. Splitting tensile strengths of the specimens

\subsection{Three-Point Flexural Strength}

One of the important tests for evaluation of concrete performance is three-point flexural test. Simple preparation and testing of the specimens are the advantages of three-point flexural strength test. A test fixture and a universal testing machine are needed to conduct this test (Figure 10). As shown in Figure 10, the specimen is placed on two pin supports and the load is applied at mid-span.

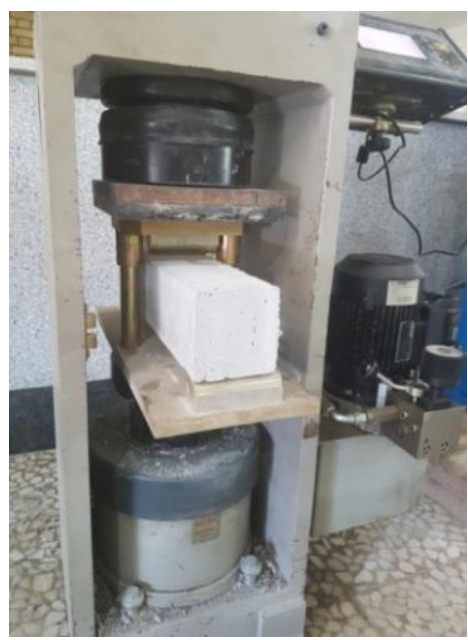

Figure 10. Three-point flexural strength test

Flexural strength, $\sigma_{f}$, can be provided by this test as proposed in Eq. 2.

$$
\sigma_{f}=\frac{3 F L}{2 b d^{2}}
$$

where,

$\mathrm{F}$ is load at a given point, $\mathrm{L}$ is support span, $\mathrm{b}$ is width of the beam and $d$ is depth of the beam.

Three-point flexural strengths of the specimens were calculated based on Eq. 2 and presented in Figure 11. It was seen that in W, Y and WY specimens, 0.5, 0.25 and $0.25 \%$ had the highest flexural strengths, respectively. 


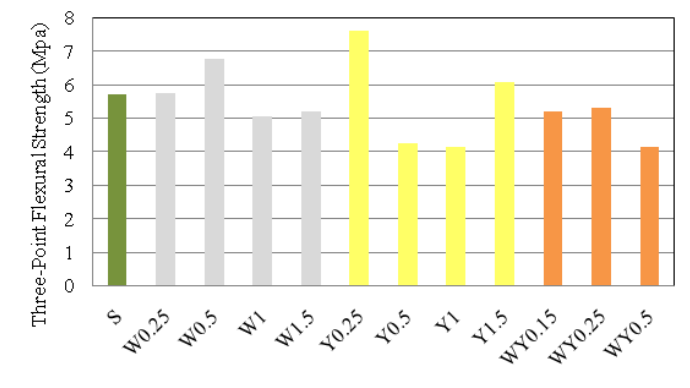

Figure 11. Three-point flexural strength of the specimens

\section{CONCLUSIONS}

16 types of the concrete mixtures were casted. Each type contained 9 cubes, one cylinder and one flexural beam specimens.

Cubes were tested after 7, 14 and 28 days for compressive strength.

Moreover, splitting tensile strength and flexural strength were obtained from testing cylinder and flexural beam specimens after 28 days. The following conclusions can be drawn:

1. By substituting a portion of water content with albumen, it was seen that the specimens with $0.5 \%$ albumen had the highest compressive strengths among $\mathrm{W}$ series after 7, 14 and 28 days.

2. The specimens with $0.25 \%$ yolk instead of a portion of water had the maximum compressive strengths at each age.

3. In WY series which contained albumen and yolk together, $0.15 \%$ gave the best values for compressive strength.

4. Between all 16 mixtures, control specimen, W0.25 and W0.5 had similar 28-days compressive strengths.

5. By testing cylindrical specimens, it was seen that $1 \%$ albumen, $0.25 \%$ yolk and $0.15 \%$ albumen and yolk had the highest splitting tensile strengths in each series.

6. By substituting $1 \%$ of water with albumen, the maximum tensile strength was achieved between 16 specimens. Moreover, splitting tensile strength of W1 specimen was $8.7 \%$ higher than control specimen.

7. Testing flexural beams showed that the specimens with $0.5 \%$ albumen, $0.25 \%$ yolk and $0.25 \%$ albumen and yolk had the highest three-point flexural strengths in each series.

8. By considering compressive strengths, splitting tensile strengths and three-point flexural strengths of all 16 mixtures, it could be concluded by substituting $0.5 \%$ of water with albumen, compressive strength of the specimen was similar to control specimen. Besides, tensile strength and flexural strength were
$7.2 \%$ and $18.9 \%$ higher than control specimen, respectively.

9. Because of fat in the camel milk, it was not a good choice instead of a portion of water.

\section{REFERENCES}

Bing, L.Y., 2010.Effect of foamed concrete with egg albumen. Master of Science Dissertation, University Malaysia Pahang.

Bouzoubaa, N., and Lachemi, M., 2001. Self-compacting concrete incorporating high volumes of class $\mathrm{F}$ fly ash: Preliminary results. Cement and Concrete Research, vol. 31, no. 3, pp. 413-420.

Dhanalakshmi, M., Sowmya, N.J., and Chandrashekar, A., 2015. A comparative study on egg shell concrete with partial replacement of cement by fly ash. International Journal for Research in Applied Science and Engineering Technology, vol. 3, pp.12-20.

Dixit, M., Meena, A., Malik, A., Chhinderpal, and Sundesha, K., 2016. Effect of using egg shell powder and micro silica partially in place of cement in M25 concrete. International Journal of Civil Engineering, vol. 3, pp. 278-282.

Gowsika, D., Sarankokila, S., and Sargunan, K., 2014. Experimental investigation of egg shell powder as partial replacement with cement in concrete. International Journal of Engineering Trend and Technology, vol. 14, No.2, pp. 65-68.

Ikotun, B.D., 2009.The effect of a modified zeolite additive as a cement and concrete improver. Master of Science Dissertation, Faculty of Engineering and the Built Environment, University of the Witwatersrand, Johannesburg.

Li, G., 2004. Properties of high-volume fly ash concrete incorporating nano-SiO2.Cement and Concrete Research, vol. 34, no. 6, pp. 1043-1049.

Markiv, T., Sobol, K., Franus, M., and Franus, W., 2016. Mechanical and durability properties of concretes incorporating natural zeolite. Archives of Civil and Mechanical Engineering, vol. 16, pp. 554-562.

Mehta, P.K., 1982. Properties of Portland cement concrete containing fly ash and condensed silica-fume. Cement and Concrete Research, vol. 12, no. 5, pp. 587-595.

Meyer, C., and Xi, Y., 1999. Use of recycled glass and fly ash for precast concrete. Journal of Materials in Civil Engineering, vol. 11 , no. 2 .

Qureshi, A.M., Sharma, Y.V., Khan, S.R., and Sontakke, B.M., 2015. An experimental investigation to check the effect of egg shell powder and rice husk ash on property of concrete. International Journal on Recent and Innovation Trends in Computing and Communication, vol. 3, pp. 67-70.

Siang, T.E., 2010.Effect of coconut fiber and egg albumen in concrete for greener environment. Master of Science 
Dissertation, University Malaysia Pahang.

Teixeira, E.R., Mateus, R., Camoes, A.F., Braganca, L., and Branco, F.G., 2016.Comparative environmental life-cycle analysis of concretes using biomass and coal fly ashes as partial cement replacement material. Journal of Cleaner Production, vol. 112, pp. 2221-2230.

Thomas, M.D.A., and Bamforth, P.B., 1999. Modelling chloride diffusion in concrete: Effect of fly ash and slag. Cement and Concrete Research, vol. 29, no. 4, pp. 487-495.

Valipour, M., Shekarchi, M., and Arezoumandi, M., 2017. Chlorine diffusion resistivity of sustainable green concrete in harsh marine environments. Journal of Cleaner Production, vol. 142, no. 4, pp. 4092-4100.

Yusef, N., 2014.The effect of egg and lime on the compressive strength of mortar. Master of science Thesis, Addis Araba University. 